\title{
Evidence that trees do not shift carbon allocation from stem support to foliage under competition
}

\author{
Thomas J Dean ( $\nabla$ fwdean@lsu.edu ) \\ Louisiana State University \\ Constance A. Harrington \\ USDA Forest Service Pacific Northwest Research Station \\ Anthony W. D'Amato \\ University of Vermont \\ Brian J. Palik \\ USDA Forest Service Northern Research Station
}

\section{Research Article}

Keywords: Growth dominance index, competition, allocation, relative height growth, growth

Posted Date: February 15th, 2022

DOl: https://doi.org/10.21203/rs.3.rs-1297213/v1

License: (9) (1) This work is licensed under a Creative Commons Attribution 4.0 International License. Read Full License 


\section{Abstract}

Do trees adjust support costs to the stem in order to maintain or boost allocation to foliage to compete for light? This question was addressed with data collected from three, long-term studies investigating the growth effects of controlled levels of competition for Alnus rubra, Pseudotsuga menziesii, and Pinus resinosa. Costs and benefits of marginal height were defined as the stem volume and foliage added when trees grew $1 \mathrm{~m}$ in height, respectively. Effects of competition effects on the distribution of these variables within tree populations were evaluated with growth dominance indexes $\left(G_{d v / d h}\right.$ and $G_{d A l / d v}$, respectively). Competition effects on the distribution of relative height growth $\left(G_{d g}\right)$ were also evaluated to verify mode of competition. The hypothesized simple tradeoff between marginal height cost and marginal height benefit was not supported with these data. Instead, $G_{d v / d h}$ and $G_{d A l / d h}$ were linearly related for all three species. The values of $G_{d h}$ were generally positive for all species supporting asymmetric competition within these plots. The strength of support for this hypothesis varied by species, however, with the shade intolerant $A$. rubra providing the strongest support and the more shade tolerant $P$. menziesii providing the least support. The age-adjusted values of $P$. menziesii of $\mathrm{G}_{\mathrm{dh}}$ were only significantly greater than zero in the unthinned, control plots. The results suggest that competition effects on marginal height benefit translate to marginal height cost through biomechanical relationships between crown size and structure and stem dimensions. Competitive effects on stand dynamics can therefore be linked to a basic tree morphology that scales with height. Realized additions of stem volume and foliage per growing season are subsequently determined by the distribution of relative height growth.

\section{Key Message}

When competing for light, trees growing in even-aged monocultures do not appear to shift allocation from stem growth to foliage growth. Marginal height cost (change in stem volume per change in height) and marginal height benefit (net change in leaf area per change in height) covary within trees, resulting in similar distribution inequities among trees experiencing a given level of competition. Marginal height cost and benefit represent a dynamic base morphology that scales with tree height. The sensitivity of relative tree height to competition appears to vary with shade tolerance. Stand dynamics can be separated into a scalable morphology and competition effects on relative height growth.

\section{Introduction}

Height conveys obvious competitive advantages to trees over shrubs and forbs, and while much research has been devoted to understanding the limits of height growth, the mechanisms involved to compete with their congeners are more applicable to forest dynamics and production ecology. The physics of maintaining foliage above competitors requires trees to commit substantial portions of carbohydrate to the stem. These support costs can be estimated using simple mechanics. For example, based on simple column mechanics, critical buckling height is a function of stem diameter at the base of the tree raised to the 2/3 power (McMahon and Kroneur 1976; Dean and Long 1986). Mechanics dictate that stem costs increase with height (King 2005), and the most notable manifestation of this cost is Eichorn's rule where stand production is closely related to stand height for unthinned or lightly thinned stands (Skovsgaard and Vanclay 2008). Benefits obviously exceeds this cost in living trees, but can trees adjust the support costs of stem volume in order to obtain better benefit-cost ratios than their competitors and thus grow taller than their neighbors?

We addressed this question by analyzing competition effects on the stem volume added per unit height growth, the leaf area added per unit height growth, and relative height growth with data collected in three studies where competition was manipulated by planting trees at different spacings or by thinning plots to various ranges of growing stock. Volume added per unit of height growth was considered a marginal height cost, and the leaf area added per unit of height growth was considered a marginal height benefit. Both of these parameters relate allocation to structural changes and describe a dynamic aboveground morphology when competing with neighbors. Periodic growth in stem volume and net leaf area then are direct functions of relative height growth calculated as periodic annual height increment divided by initial height. This conceptualization separates aboveground tree growth into two components: dynamic tree morphology and height growth Following Ford (2014), competition is indicated when dynamic tree morphology and height growth are distributed unequally according to a tree's height rank in a population.

Prior studies indicate that competition affects allocations to stem volume and foliage and most likely the relative costs and benefits associated with height growth. When analyzed with height, the annual allocation to foliage decreased and that to stemwood increased with tree height in Pinus sylvestris L. (Vanninen and Makela 2005). Allocation in that study was calculated as a percentage of gross tree growth without allowances for respiration losses. Trouve et al. (2015) analyzed allocation variables that resemble marginal height cost with plots of periodic changes in height versus periodic changes in stem diameter for Quercus patraea (Liebl.) trees growing in various conditions. They showed that diameter growth increased rapidly with increasing rate of height growth and that competition substantially affected the rates of change in height increment and diameter increment. 
Competition has been shown to affect relative height growth. Cannell et al. (1984), planted Pinus sitchensis and Pinus contorta seedlings on a $14 \mathrm{~cm} \times 14 \mathrm{~cm}$ grid and followed their growth for 5 and 7 years, respectively. They found that competition accounted for $28 \%$ and $35 \%$ of the variation in relative height growth during the course of the study. Cole and Lorimer (1994) concluded that height increment was significantly related to initial height and the percent of crown exposed to the sky; a condition that is a function of a tree's height rank within a population. Other measures of social position within a population, such as the sum basal area of larger trees, have also been shown to affect height increment (Uzoh and Oliver 2006).

The interaction of marginal height costs and benefits with tree height in competing populations have been explored with game theory because optimizing structure for a single tree may not be optimal when other trees are also competing for light. Game theoretics for height incorporate the off-setting effect of costs and benefits associated with height in populations experiencing asymmetric competition for light (Falster and Westoby 2003). The games include cost-benefit functions that seek the height that shades out invaders by maximizing current annual increment (King 1990), productive mass (e.g., foliage) (Makela 1985), or net carbon assimilation (Iwasa et al. 1984). The games must make several simplifying assumptions to be tractable such as opaque crowns and proportions of stemwood and foliage allocation summing to one that may not lead to realistic outcomes. Furthermore, game theoretics do not provide for the possibility of competition changing the allocation functions, which could also change game outcomes.

Competition effects on individual trees are best analyzed within the context of a population where the intensity and mode of competition can be inferred from measures of size inequity. According to Weiner and Thomas (1986), when inequity increases with stand density, competition is asymmetric, and when inequity is independent of stand density, competition is symmetric. The degree of inequity is related to the intensity of competition. Inequity can be measured by the coefficient of variation of a particular plant metric or the Gini coefficient which measures the deviation of plant size from a 1:1 line for cumulative size and proportion of the population for size-ranked data. Growth dominance, a similar but more flexible index, was developed by Binkley (2004). This index has similar implications regarding competition and resource utilization as the Gini coefficient but with two important differences: (1) growth dominance measures the inequity of the distribution of a functional trait such as tree growth relative to initial mass and (2) growth dominance can be negative as well as positive. The values are similar in that positive values indicate asymmetric competition and zero values indicate symmetric competition (Fernandez-Tscheider and Binkley 2018).

The objective of this study is to examine the response of the distribution of marginal height cost and marginal height benefit among trees to determine whether (1) competition changes the overall morphology to maintain adequate illumination of foliage; (2) the magnitude of adjustments are related to the intensity of competition; and (3) the distribution of relative height growth changes with intensity of competition. Growth dominance indexes were calculated for each parameter relative to initial height to measure changes in the distribution of these parameter in response to competition. The indexes were calculated with data collected from long-term, permanent-plot data from three species. Each study followed the growth of each tree, allowing marginal height cost, and marginal height benefit, and relative height growth to be calculated for each tree over repeated measurement intervals.

\section{Methods}

\section{Data sources}

Three long-term data sets spanning up to three decades of repeated measurements were used for these analyses. These data sets are rare in that the data were collected across the range of developmental stages that can be statistically analyzed. The three data sets were collected from an initial planting density study for Alnus rubra Bong. and two levels of growing stock studies: one established in three naturally regenerated, Pseudotsuga menziesii var. menziesii stands and another in an artificially regenerated Pinus resinosa Ait. plantation. For all, dendrometric data were collected repeatedly on trees growing at different spacings. In the $A$. rubra study, trees were planted at four square spacings $(1.8 \mathrm{~m}, 2.8 \mathrm{~m}, 4.2 \mathrm{~m}$, and $6.4 \mathrm{~m})$ and allowed to develop without interference. In the $P$. menziesii and the $P$. resinosa studies, trees were thinned to a series of growing-stock levels. The growing-stock levels in the $P$. menziesii study were set relative to four, fixed percentages of plot growth relative to the unthinned control plots. These percentages were $10 \%, 30 \%, 50 \%$, and $70 \%$. In the $P$. resinosa study, growing stock was defined as basal area per hectare. Five levels of growing stock were assigned to the plots established in this study (7, 14, 21, 28, $35 \mathrm{~m}^{2} /$ ha) plus an unthinned control.

The biological characteristics of $A$. rubra are described by Harrington (1990). Alnus rubra is a common hardwood species that is native to the coastal region of the northern Pacific coast in North America. It is relatively short lived, maturing between 60 to 70 years old, and it is intolerant to shade. It is unique in that it fixes nitrogen. Height growth is rapid when young, slowing significantly after the juvenile stages. Typical heights at 50 years old range between 18 to $37 \mathrm{~m}$.

The A. rubra study was established by the Hardwood Silviculture Cooperative at Oregon State University. Details of the study were described by Weiskittel et al. (2009). Plots varied from 0.13 ha to 0.20 ha and were measured every 3-5 years beginning at age 3 years. Within the 22 
installations, one replicate of each planting density was randomly assigned to a plot. Measurement protocols are also described by Weiskittel et al. (2009) and summarized by Dean et al. (2013). The number of trees measured in each plot varied by planting density and age, ranging from a maximum of 688 at age 4 in the plots with the closest initial spacing to a minimum of 45 at age 13 in the plots with the widest spacing (Table 1).

Table 1

Minimums, maximums, and means of numbers of trees per plot, total tree height, and diameter at breast height (dbh) for each measurement period by treatment. Only data from one installation is shown for Pseudotsuga menziesii because measurements were collected at different ages at the other 2 installations. Data shown for the Rocky Brook installation is typical.

\begin{tabular}{|c|c|c|c|c|c|c|c|c|c|c|c|c|c|c|}
\hline & & & Age & & & & & & & & & & & \\
\hline & & & 4 & & & 7 & & & 10 & & & 13 & & \\
\hline Species & Spacing & & Min & Median & Max & Min & Median & Max & Min & Median & Max & Min & Median & Max \\
\hline \multirow{4}{*}{\multicolumn{2}{|c|}{$\begin{array}{l}\text { Alnus } \\
\text { rubra }\end{array}$}} & & & & & & & & & & & & & \\
\hline & & Trees/plot & 32 & 51 & 86 & 32 & 50 & 83 & 32 & 51 & 82 & $45^{\$}$ & 49 & 53 \\
\hline & & $\begin{array}{l}\text { Height } \\
(\mathrm{m})\end{array}$ & 0.3 & 3.0 & 3.0 & 0.8 & 7.4 & 15.3 & 3.2 & 9.2 & 19.5 & 8.4 & 14.6 & 17.6 \\
\hline & & $\mathrm{dbh}(\mathrm{cm})$ & 0.5 & 1.8 & 6.6 & 0.5 & 7.1 & 18.5 & 2.0 & 11.7 & 26.9 & 9.1 & 20.8 & 30.5 \\
\hline \multicolumn{15}{|c|}{$4.2 \mathrm{~m}$} \\
\hline & & Trees/plot & 65 & 97 & 138 & 59 & 94 & 136 & 57 & 96 & 133 & 80 & 94 & 110 \\
\hline & & $\begin{array}{l}\text { Height } \\
(\mathrm{m})\end{array}$ & 0.4 & 3.0 & 7.4 & 1.7 & 7.4 & 14.4 & 2.6 & 11.0 & 18.0 & 6.8 & 14.7 & 20.6 \\
\hline & & $\mathrm{dbh}(\mathrm{cm})$ & 0.5 & 1.8 & 7.1 & 0.5 & 7.1 & 17.8 & 1.3 & 11.9 & 23.9 & 5.6 & 17.0 & 27.9 \\
\hline \multicolumn{15}{|c|}{$2.8 \mathrm{~m}$} \\
\hline & & Trees/plot & 129 & 203 & 296 & 129 & 200 & 294 & 139 & 204 & 292 & 189 & 192 & 195 \\
\hline & & $\begin{array}{l}\text { Height } \\
(\mathrm{m})\end{array}$ & 0.3 & 3.3 & 8.2 & 1.4 & 8.0 & 14.3 & 2.3 & 10.4 & 18.8 & 6.4 & 13.7 & 22.6 \\
\hline & & $\mathrm{dbh}(\mathrm{cm})$ & 0.5 & 1.8 & 7.4 & 0.5 & 7.1 & 17.5 & 1.0 & 10.4 & 22.1 & 3.6 & 14.7 & 24.9 \\
\hline \multicolumn{15}{|c|}{$1.8 \mathrm{~m}$} \\
\hline & & Trees/plot & 195 & 388 & 688 & 192 & 374 & 683 & 218 & 367 & 658 & 287 & 310 & 332 \\
\hline & & $\begin{array}{l}\text { Height } \\
\text { (m) }\end{array}$ & 0.3 & 3.4 & 7.9 & 1.7 & 7.4 & 14.4 & 2.6 & 9.2 & 18.6 & 3.9 & 11.1 & 21.1 \\
\hline & & $\mathrm{dbh}(\mathrm{cm})$ & 0.5 & 2.0 & 7.1 & 0.5 & 6.3 & 14.7 & 1.3 & 8.4 & 18.3 & 2.3 & 11.2 & 20.3 \\
\hline
\end{tabular}




\begin{tabular}{|c|c|c|c|c|c|c|c|c|c|c|c|c|c|c|}
\hline & & & Age & & & & & & & & & & & \\
\hline & $\begin{array}{l}\text { Growing } \\
\text { stock }\end{array}$ & & 28 & & & 39 & & & 45 & & & 58 & & \\
\hline \multirow{4}{*}{\multicolumn{2}{|c|}{$\begin{array}{l}\text { Pseudotsuga } \\
\text { menziesii }\end{array}$}} & & & & & & & & & & & & & \\
\hline & & Trees/plot & 63 & 63 & 79 & 20 & 24 & 35 & 14 & 17 & 25 & 9 & 11 & 15 \\
\hline & & $\begin{array}{l}\text { Height } \\
\text { (m) }\end{array}$ & 5.6 & 9.2 & 13.4 & 9.8 & 15.2 & 19.8 & 11.6 & 19.1 & 23.2 & 18.7 & 25.7 & 32.0 \\
\hline & & $\mathrm{dbh}(\mathrm{cm})$ & 6.9 & 11.2 & 17.3 & 11.9 & 19.8 & 29.0 & 13.7 & 25.1 & 35.3 & 23.1 & 35.3 & 45.7 \\
\hline \multicolumn{15}{|c|}{$30 \%$} \\
\hline & & Trees/plot & 73 & 74 & 78 & 37 & 49 & 51 & 32 & 45 & 45 & 25 & 32 & 35 \\
\hline & & $\begin{array}{l}\text { Height } \\
\text { (m) }\end{array}$ & 5.7 & 9.4 & 21.7 & 9.5 & 15.1 & 19.7 & 11.6 & 18.0 & 23.6 & 13.7 & 22.9 & 31.0 \\
\hline & & $\mathrm{dbh}(\mathrm{cm})$ & 5.3 & 11.2 & 18.8 & 8.6 & 17.8 & 25.9 & 10.4 & 20.8 & 31.2 & 14.2 & 27.4 & 39.4 \\
\hline \multicolumn{15}{|c|}{$50 \%$} \\
\hline & & Trees/plot & 63 & 73 & 73 & 52 & 63 & 69 & 45 & 59 & 66 & 35 & 38 & 60 \\
\hline & & $\begin{array}{l}\text { Height } \\
(\mathrm{m})\end{array}$ & 5.0 & 9.5 & 14.4 & 7.9 & 14.8 & 21.1 & 9.2 & 17.6 & 25.0 & 10.4 & 22.0 & 30.3 \\
\hline & & $\mathrm{dbh}(\mathrm{cm})$ & 6.4 & 11.2 & 18.8 & 8.9 & 16.4 & 26.7 & 8.9 & 18.9 & 31.8 & 9.9 & 22.6 & 40.1 \\
\hline \multicolumn{15}{|c|}{$70 \%$} \\
\hline & & Trees/plot & 78 & 78 & 80 & 72 & 75 & 75 & 69 & 72 & 75 & 56 & 65 & 72 \\
\hline & & $\begin{array}{l}\text { Height } \\
(\mathrm{m})\end{array}$ & 5.2 & 9.8 & 13.8 & 8.8 & 16.1 & 21.3 & 10.4 & 19.1 & 24.6 & 12.2 & 24.6 & 31.7 \\
\hline & & $\mathrm{dbh}(\mathrm{cm})$ & 5.6 & 11.2 & 19.1 & 9.4 & 17.1 & 28.4 & 9.7 & 20.1 & 33.0 & 11.2 & 24.6 & 41.7 \\
\hline \multicolumn{15}{|c|}{$100 \%$} \\
\hline & & Trees/plot & 168 & 178 & 212 & 158 & 158 & 207 & 134 & 138 & 187 & 95 & 100 & 127 \\
\hline & & $\begin{array}{l}\text { Height } \\
(\mathrm{m})\end{array}$ & 4.4 & 8.7 & 16.1 & 5.8 & 13.0 & 23.5 & 6.8 & 15.3 & 26.5 & 9.2 & 20.7 & 33.7 \\
\hline & & $\mathrm{dbh}(\mathrm{cm})$ & 4.1 & 8.6 & 22.9 & 3.8 & 11.4 & 31.0 & 4.1 & 13.5 & 34.0 & 4.8 & 17.8 & 40.4 \\
\hline
\end{tabular}

Table 1 (cont'd) 


\begin{tabular}{|c|c|c|c|c|c|c|c|c|c|c|c|c|c|c|}
\hline & & & Age & & & & & & & & & & & \\
\hline & $\begin{array}{l}\text { Basal } \\
\text { area }\end{array}$ & & 50 & & & 65 & & & 70 & & & 80 & & \\
\hline \multirow{4}{*}{\multicolumn{2}{|c|}{$\begin{array}{l}\text { Pinus } \\
\text { resinosa }\end{array}$}} & & & & & & & & & & & & & \\
\hline & & Trees/plot & 8.0 & 12.0 & 23.0 & 8.0 & 12.0 & 23.0 & 7.0 & 12.0 & 23.0 & 7.0 & 12.0 & 23.0 \\
\hline & & $\begin{array}{l}\text { Height } \\
(\mathrm{m})\end{array}$ & 12.8 & 17.8 & 20.7 & 14.0 & 20.1 & 22.9 & 14.3 & 21.0 & 22.7 & 17.4 & 23.5 & 26.5 \\
\hline & & $\mathrm{dbh}(\mathrm{cm})$ & 10.9 & 22.6 & 32.3 & 14.5 & 30.5 & 40.6 & 16.3 & 33.9 & 44.5 & 19.6 & 39.1 & 50.3 \\
\hline \multicolumn{15}{|c|}{$14 \mathrm{~m}^{2} / \mathrm{ha}$} \\
\hline & & Trees/plot & 16.0 & 24.0 & 41.0 & 16.0 & 24.0 & 41.0 & 16.0 & 24.0 & 41.0 & 16.0 & 24.0 & 41.0 \\
\hline & & $\begin{array}{l}\text { Height } \\
(\mathrm{m})\end{array}$ & 15.9 & 18.0 & 20.1 & 16.2 & 20.9 & 23.2 & 18.9 & 22.1 & 23.5 & 20.7 & 23.9 & 26.2 \\
\hline & & $\mathrm{dbh}(\mathrm{cm})$ & 10.7 & 22.6 & 35.1 & 14.5 & 29.7 & 42.7 & 15.7 & 32.5 & 45.7 & 17.0 & 36.6 & 49.8 \\
\hline & \multicolumn{14}{|l|}{$21 \mathrm{~m}^{2} / \mathrm{ha}$} \\
\hline & & Trees/plot & 30.0 & 42.5 & 66.0 & 21.0 & 30.0 & 48.0 & 16.0 & 24.0 & 39.0 & 13.0 & 16.5 & 31.0 \\
\hline & & $\begin{array}{l}\text { Height } \\
(\mathrm{m})\end{array}$ & 10.7 & 17.9 & 19.5 & 15.4 & 20.9 & 23.5 & 16.2 & 22.0 & 24.1 & 17.6 & 23.7 & 26.8 \\
\hline & & $\mathrm{dbh}(\mathrm{cm})$ & 9.4 & 21.6 & 31.5 & 10.2 & 27.1 & 38.4 & 10.2 & 29.2 & 41.4 & 11.2 & 32.5 & 45.7 \\
\hline & \multicolumn{14}{|l|}{$28 \mathrm{~m}^{2} / \mathrm{ha}$} \\
\hline & & Trees/plot & 44.0 & 55.0 & 72.0 & 34.0 & 42.0 & 56.0 & 28.0 & 33.0 & 48.0 & 21.0 & 25.0 & 39.0 \\
\hline & & $\begin{array}{l}\text { Height } \\
(\mathrm{m})\end{array}$ & 15.7 & 18.0 & 20.1 & 18.4 & 20.9 & 23.9 & 19.4 & 22.0 & 26.8 & 20.9 & 23.8 & 26.8 \\
\hline & & $\mathrm{dbh}(\mathrm{cm})$ & 10.7 & 22.4 & 32.0 & 11.9 & 26.9 & 36.1 & 12.7 & 28.7 & 38.1 & 13.5 & 32.3 & 40.9 \\
\hline & \multicolumn{14}{|l|}{$35 \mathrm{~m}^{2} / \mathrm{ha}$} \\
\hline & & Trees/plot & 63.0 & 75.0 & 99.0 & 49.0 & 55.0 & 78.0 & 41.0 & 48.0 & 65.0 & 33.0 & 40.0 & 57.0 \\
\hline & & $\begin{array}{l}\text { Height } \\
(\mathrm{m})\end{array}$ & 14.9 & 17.9 & 20.8 & 17.4 & 17.4 & 24.7 & 18.3 & 22.0 & 24.8 & 19.8 & 23.8 & 28.1 \\
\hline & & $\mathrm{dbh}(\mathrm{cm})$ & 10.7 & 21.3 & 30.5 & 11.7 & 25.1 & 35.6 & 11.7 & 27.2 & 37.3 & 14.7 & 30.0 & 40.4 \\
\hline & \multicolumn{14}{|l|}{ Control } \\
\hline & & Trees/plot & 76.0 & 89.0 & 118.0 & 73.0 & 84.5 & 109.0 & 69.0 & 82.0 & 105.0 & 66.0 & 74.5 & 91.0 \\
\hline & & $\begin{array}{l}\text { Height } \\
(\mathrm{m})\end{array}$ & 14.3 & 18.0 & 22.0 & 18.6 & 20.9 & 25.6 & 19.8 & 22.0 & 27.1 & 22.1 & 23.8 & 29.9 \\
\hline & & $\mathrm{dbh}(\mathrm{cm})$ & 9.9 & 22.5 & 32.3 & 12.2 & 25.4 & 36.3 & 12.2 & 26.9 & 37.8 & 16.3 & 29.0 & 40.1 \\
\hline
\end{tabular}

$\$$ The minimum number of trees increased from age 10 to 13 because some plots across the installations were not measured at age 13 . The number of trees per plot decreased or remained the same through time for individual installation.

The biological characteristics of $P$. menziesii are described by Hermann and Lavender (1990). The levels of growing stock study was established in coastal $P$. menziesii, var. menziesii which is a different variety than $P$. menziesii var. glauca growing east of the Cascade Mountains in the northwest region of North America. Coastal $P$. menziesii is considered intermediate in shade tolerance and is very long lived, commonly living for 500 years. Old-growth trees can reach 76-m tall. Highest height increments are reached between 20 and 30 years of age.

The P. menziesii data used in this study was collected in the three installations of the Levels of Growing Stock Study established on National Forests in the Pacific Northwest region of the United States (Harrington 2018). These installations and others established by Weyerhaeuser Company, Oregon State University, and the Canadian Forest Service comprised the Douglas-fir Levels of Growing Stock Study (LOGS) 
described by Curtis and Marshall (1986). The three USDA Forest Service installations were established in Washington and Oregon on the Olympic (Rocky Brook installation), Gifford Pinchot (Iron Creek installation), and the Umpqua (Stampede Creek installation) National Forests. Within each installation, levels of growing stock were randomly assigned to three, 0.08 -ha plots. Trees in the plots had naturally regenerated. Measurement frequency varied by installation because thinning intervals were set according to height increment. The number of trees measured at the Rocky Brook installation varied from a maximum of 212 at age 28 years for the unthinned control to a minimum of 9 at age 58 years for the $10 \%$ level of the growing stock (Table 1 ). These numbers are typical of the other two locations.

The biological characteristics of $P$. resinosa are described by Rudolf (1990). The biological range of $P$. resinosa is in the northeastern and north central regions of North America. $P$. resinosa is intolerant to shade, but it does not seem to be as intolerant as $A$. rubra. Trees as tall as $43 \mathrm{~m}$ have been recorded, but heights of 21 to $24 \mathrm{~m}$ are more typical at maturity. Height increment slows significantly after 100 years of growth. The maximum life span of $P$. resinosa is substantially shorter than that of $P$. menziesii and is at least twice as long as that of $A$. rubra.

The $P$. resinosa study was also designed to examine the effects of maintaining fixed levels of growing stock on tree and stand growth. This study was established in the Birch Lake plantation planted with 2,500 trees per hectare on the Superior National Forest in northern Minnesota, USA. The six basal area treatments were assigned at random to $18,0.8$ hectare plots. These plots were split into thirds to accommodate three thinning methods: low, crown, and combined. Plots were thinned about every 10 years, and trees were measured every 5 10 years. The number of trees measured at each measurement period varied from a maximum of 118 at age 45 in the unthinned plots to a minimum of 7 at age 80 for the $7 \mathrm{~m}^{2} /$ ha basal area treatment (Table 1 ).

Variables

Relative height increment was calculated for each tree surviving between measurement periods. Equations to calculate missing heights were developed with height data that were measured on a subset of trees during each measurement period. The height equation for $A$. rubra was developed by the OSU Hardwood Research Cooperative. Equations to calculate missing heights for $P$. menziesii and $P$. resinosa are described by Dean et al. (2021). Relative height increment for these analyses is simply height increment per initial height at the beginning of each measurement period.

Volume increment per meter of height growth was calculated for each tree in the plot. Tree-volume equations for $A$. rubra, $P$. menziesii, and $P$. resinosa are described by Hibbs et al. (2007), Bruce and DeMars (1974), and Fowler (1997), respectively. Volume increment per height increment was calculated for each tree that survived between measurement periods.

Net leaf area added per meter of height increment was calculated for each tree that survived between measurement intervals. Leaf area per tree was calculated with regression equations based on combinations of $\mathrm{dbh}$ and height. The equation for $A$. rubra was developed by Helgerson et al. (1988). The equation for P. menziesii was developed by Dean et al. (2021) based on data collected by Maguire and Bennett (1996), and the equation for $P$. resinosa was developed by Penner and Deblonde (1996).

Dominance indexes were calculated from cumulative proportions of the height increment versus initial height or relative height growth ( $\mathrm{G}_{\mathrm{dh}}$ ), marginal height cost for height ranked trees $\left(G_{d v / d h}\right)$, and marginal height benefit for height-ranked trees $\left(G_{d A l} / d h\right)$ for each plot for each measurement period. Forrester (2019) calculated growth dominance for relative basal area growth, for example. The three dominance coefficients were calculated with the alternative equation proposed by Fernandez et al. (2011).

Analyses

Tests for competition effects on $\mathrm{G}_{\mathrm{dv} / \mathrm{dh}}$ and $\mathrm{G}_{\mathrm{dh}}$ were conducted with linear mixed models with repeated measures suggested by Littell et al. (2006). The null hypothesis of no competition effect on the least-square means of $G_{d v / d h}$ and $G_{d h}$ was rejected if the probability of greater values of $F$ exceeded 0.10 . The least-square means represented age-adjusted means values of $G_{d v / d h}$ and $G_{d h}$ for each level of competition. Post-hoc means testing was conducted by calculating the probability of greater values of t for all pairs of means. Standard errors of the ageadjusted means allowed t-tests of the null hypothesis that the mean equal to zero. Data for the mixed-model analysis were the mean values across installation for each initial planting density and measurement period for the $A$. rubra data; the values averaged over the three replications of each level of growing stock, installation, and measurement period for the $P$. menziesii; and the values averaged over the three replications of each residual basal area, thinning method, and measurement period for the $P$. resinosa data. Standard errors of these means were used to conduct two-tailed, t-tests for the null hypothesis of no difference with zero.

The existence of competition-induced tradeoffs between marginal height cost and marginal height benefit was tested with linear, mixedmodel regression analysis with repeated measures with competition treatment as a categorical variable. The growth dominance index for 
marginal height cost $\left(G_{d v / d h}\right)$ was regressed on $G_{d A l / d h}$ with individual plot as the repeated unit. A simple tradeoff between costs and benefits would be indicated with either a zero or negative slope between the variables.

\section{Results}

Marginal height cost

The mixed-model analyses of variance rejected the null hypothesis of no planting density or level of growing stock effect on growth dominance index for marginal height cost $\left(\mathrm{G}_{\mathrm{dv} / \mathrm{dh}}\right)$ (Figure 1). This indicates that at least one treatment significantly affected the ageadjusted mean value of $G_{d v / d h}$ for a treatment. In the A. rubra study, all initial spacings significantly affected $G_{d v / d h}$ while in the P. menziesii study, all but the $30 \%$ level of growing stock significantly affected the value. In the $P$. resinosa study, all but the 7 and $21 \mathrm{~m}^{2} /$ ha residual basal areas significantly affected the age-adjusted means. In all studies, the age-adjusted values of $\mathrm{G}_{\mathrm{dv} / \mathrm{dh}}$ increased with increasing level of competition. The increase with competition is not continuous especially for the lowest levels of competition for the coniferous species.

For the $P$. resinosa study, four means averaged across the three blocks for each thinning method and residual density were negative and significantly different from zero. No other significantly negative values of $\mathrm{G}_{\mathrm{dc} / \mathrm{dh}}$ were observed. Three of these negative values were observed in the lowest residual basal area. The other negative value was detected in the $21 \mathrm{~m}^{2} /$ ha residual basal area.

The means of the three replications within an installation for each thinning treatment showed no significant relationship with age for the two coniferous species (Figure 1). The means across the installations for each initial spacing in the $A$. rubra study did significantly covary with age for three of the initial spacings; however, the slope between the values of $G_{d v / d v}$ was negative in two widest spacings and positive for the narrowest spacing. In this later case, the value for the last measurement period had a strong influence on the slope of the line. Without the last measurement, slope for the closest spacing would appear to be zero.

Marginal height benefit

The growth dominance index for marginal height benefit and $G_{d v / d h}$ respond similarly to competition to the extent that $G_{d A / / d h}$ is nearly equal to $G_{d v / d h}$ as pairs of values lie mostly along a 1:1 line between the two values (Figure 2). Competition significantly interacts with the slope for the $A$. rubra and $P$. resinosa studies (Table 2) but only due to one significant treatment effect in each study. For $A$. rubra study, the slope for the trees initially spaced at $2.8 \mathrm{~m}$ was 0.837 compared to 0.984 for the $1.8-\mathrm{m}$ spacing. For the $P$. resinosa study, the slope for the $30-\mathrm{m}^{2} /$ ha treatment was 1.843 compared to 1.14 for the unthinned control treatment. For the $P$. menziesii study, the slope for the unthinned control treatment was 1.29 with no significant treatment effects on the slope. 
Table 2

Linear, mixed-model analyses with repeated measures with the model $\left(\mathrm{G}_{\mathrm{dAl} / \mathrm{dh}}\right)_{i j}$

$=a_{l}+\beta_{i}\left(\mathrm{G}_{\mathrm{dv} / \mathrm{dh}}\right)_{i j}+b_{j}+\varepsilon_{\mathrm{ij}}$, where $\mathrm{G}_{\mathrm{dAl}}=$ growth dominance index for marginal

height benefit, $\mathrm{G}_{\mathrm{dv} / \mathrm{dh}}=$ growth dominance index for marginal height cost, $\mathrm{i}=$

planting density or level of growing stock, $\mathrm{i}=$ installation or thinning method, and $b_{j}$ and $\varepsilon_{i j}$ are random variables. Covariance is set to autoregressive to account for repeated measures.

\begin{tabular}{|c|c|c|c|c|c|}
\hline Species & Effect & df1 & df2 & F-value & $P>F$ \\
\hline \multicolumn{6}{|c|}{ Alnus rubra } \\
\hline & $\mathrm{G}_{\mathrm{dv} / \mathrm{dh}}$ & 1 & 244 & 1681.7 & $<0.001$ \\
\hline & $\mathrm{S}^{\mathrm{a}}$ & 4 & 156 & 58.83 & $<0.001$ \\
\hline & $\mathrm{G}_{\mathrm{dv} / \mathrm{dh}} \times \mathrm{S}$ & 3 & 219 & 3.47 & 0.0169 \\
\hline \multicolumn{6}{|c|}{ Pseudotsuga menziesii } \\
\hline & $\mathrm{G}_{\mathrm{dv} / \mathrm{dh}}$ & 1 & 72.2 & 153.19 & $<0.001$ \\
\hline & $\mathrm{GSL}^{\mathrm{b}}$ & 5 & 22.2 & 7.51 & 0.0003 \\
\hline & $\mathrm{G}_{\mathrm{dv} / \mathrm{dh}} \times \mathrm{GSL}$ & 4 & 61.8 & 1.42 & 0.239 \\
\hline \multicolumn{6}{|c|}{ Pinus resinosa } \\
\hline & $\mathrm{G}_{\mathrm{dv} / \mathrm{dh}}$ & 1 & 76.3 & 558.51 & $<.0 .001$ \\
\hline & $\mathrm{BA}^{\mathrm{c}}$ & 6 & 11.8 & 1.45 & 0.2763 \\
\hline & $\mathrm{G}_{\mathrm{dv} / \mathrm{dh}} \times \mathrm{BA}$ & 5 & 43.6 & 9.72 & $<0.001$ \\
\hline \multicolumn{6}{|c|}{ a Initial spacing } \\
\hline \multicolumn{6}{|c|}{ b Growing stock level in percent growth relative to control } \\
\hline${ }^{c}$ Residua & ectare & & & & \\
\hline
\end{tabular}

Relative height growth

Mixed-model analyses of variance with age as a covariate rejected the hypothesis of no competition and age effects on the growth dominance index for relative height growth $\mathrm{G}_{\mathrm{dh}}$. The least-square means of $\mathrm{G}_{\mathrm{dh}}$ significantly increased from the widest spacing to the narrowest spacing for $A$. rubra and with each increase in growing stock for $P$. menziesii (Figure 1 ). For $P$. resinosa, the least-square means of $\mathrm{G}_{\mathrm{dh}}$ decreased with each increase in residual basal area. The reduction in $\mathrm{G}_{\mathrm{dh}}$ with residual basal area seems to be due to reduced variation among the values averaged across replicates within a combination of growing-stock level, thinning method, and measurement period as competition increased. The variation between the three blocks expressed in the replicate means apparently reflected the inherent variation between the blocks at the lowest residual densities; competition effects began to overwhelm the block-to-block variation as residual thinning density increased.

The mixed-model covariate analysis also indicated that the within-measurement-period means of $\mathrm{G}_{\mathrm{dh}}$ within a density treatment significantly covaried with age for $A$. rubra and $P$. menziesii but not for $P$. resinosa. The correlation is logical for initial-spacing study for $A$. rubra because, overall stand density increases as the trees grow larger, increasing intraspecific competition. The nature of the correlation between $\mathrm{G}_{\mathrm{dht}}$ and age is different for $P$. menziesii than for $A$. rubra. For the controlled levels of growing stock, the growth dominance coefficients are less than zero: some of the means are significantly less than zero, indicating that the shorter trees are adding disproportionately more height than the taller trees. Many values are not significantly different than zero during the middle part of the study period, and some of the means are significantly greater than zero during the later measurement periods. If trees do not change rankings in initial height, the changes in growth dominance for height increment suggest that relative height growth of the middle-sized tree becomes proportional to slightly less than proportional to initial height as the trees age independent of stand density.

\section{Discussion}


These results of this study do not support the hypothesis that trees shift allocation away from stem support to improve or at least maintain light interception when competing for height. Both dominance indexes for marginal height cost $\left(\mathrm{G}_{\mathrm{dv} / \mathrm{dh}}\right)$ and for marginal height benefit $\left(\mathrm{G}_{\mathrm{dAl} / \mathrm{dh}}\right)$ increase with competition indicating that both marginal height cost and marginal height benefit decline disproportionately with decreasing height rank for all three species included in this study (Figure 2). While the results may be contrary to cost-benefit controls on height assumed in game theoretics, adjustments may still occur if competition affects the relative rates of increase between the two growth dominance indexes. All of the density treatments significantly affected the intercept of linear equations fit to the data, and in two of the three species, treatment significantly influenced the slope of the fitted lines (Table 2). Mixed-model analyses of differences between $\mathrm{G}_{\mathrm{dAl} / \mathrm{dh}}$ and $\mathrm{G}_{\mathrm{dv} / \mathrm{dh}}$ indicated significant shifts in allocation due to competition for all three studies despite increases in both growth dominance indexes with competition (Figure 4). However, only for A. rubra did marginal height cost decrease in the shorter trees faster than the decrease in marginal height benefit, though the shift appeared small. The shifts were more pronounced in $P$. menziesii and $P$. resinosa, but the effect of competition on the shift was opposite than would be expected if support is sacrificed for foliage. For these two species, marginal height benefit decreased for the shorter trees at a faster rate than marginal height cost. For both conifers, the difference between $\mathrm{G}_{\mathrm{dAl} / \mathrm{dh}}$ and $\mathrm{G}_{\mathrm{dv} / \mathrm{dh}}$ became less negative and with increasing competition actually became positive for the unthinned control treatments.

The linear relationships between $\mathrm{G}_{\mathrm{dAl} / \mathrm{dh}}$ and $\mathrm{G}_{\mathrm{dv} / \mathrm{dh}}$ indicates that, tree-by-tree, marginal height cost and marginal height benefit change similarly with competition. Many studies have shown that stem geometry is been related to the product of leaf area a tree carries and its vertical distribution (Mattheck 1990; Assmann 1970; Dean and Long 1986; Morgan and Cannell 1994; Dean et al. 2002; Lundqvist and Elfving 2010). This product scales the bending moment from wind drag through crowns such that the bending stress is constant among trees. The theoretical basis supporting this geometry is the constant-stress principle of stem formation originally proposed by Metzger (1893) where stem diameter changes to maintain a constant bending stress along the length of the stem. A similar principle is that stem diameter varies with the strain caused by bending stress (Wilson and Archer 1979). While stem form of individual trees may not strictly adhere to the constant-stress principle (West el al. 1989; Niklas and Spatz 2000), Niklas and Spatz (2012) state that the evidence based on physical properties is inconclusive in supporting or refuting the hypothesis, mainly because a number of properties, such as modulus of elasticity, cannot be directly measured at every location within the stem. Dean (2001 and 2002) and Dean et al. (2013b) demonstrate that the stand increment in stem volume or basal area is closely related to plot sums of the product of leaf area and height to the median leaf area. The relationship is evident in these data as well. For trees with measurements of live-crown ratio, linear, repeated measures regression of the log of marginal height cost on the log of the change in the product of leaf area and height to the median leaf area per unit of height increment explained $91 \%, 82 \%$, and $97 \%$ of the variation in the log of marginal height cost (Figure 5). The competition treatments significantly affect both the intercepts and the slopes of the regression with the exception of the $35 \mathrm{~m}^{2} /$ ha basal area treatment residual density in the $P$. resinosa study. This means that the effects of competition on marginal height benefit translates directly into the stem volume added with height growth.

Relative height growth

In general, these results support the hypothesis that competition increases the unequal distribution of relative height growth within plots; however, the effects are quite variable between the species. The clearest effect is seen with the $A$. rubra data. The trees for this species were considerably younger than the other species and are the most shade intolerant of the three species. The age-adjusted mean of $\mathrm{G}_{\mathrm{dh}}$ significantly increased with each decreases in initial spacing and the mean values across the installation covaried significantly with age in the two highest densities. The age-adjusted means of $\mathrm{G}_{\mathrm{dh}}$ for $P$. menziesii also were significantly affected by level of growing stock, increasing with each additional level of growing stock; however, the age-adjusted means were not significantly different than zero for all growing-stock levels with the exception of the unthinned control. Pseudotsuga menziesii is intermediate in shade tolerance, which may account for the lack of response to levels of competition lower than self-thinning. Furthermore, some of means of the three replicates of each treatment within an installation were negative and significantly different than zero in all treatments including the control treatment for the earlier measurement period. These means did trend higher with age with many not significantly different than zero.

The age-adjusted means of $\mathrm{G}_{\mathrm{dh}}$ for $P$. resinosa were all significantly different than zero and were significantly affected by competition, but the means decreased from the lowest residual basal area to the unthinned control. Pinus resinosa is not as shade tolerant as $P$. menziesii but not as intolerant to shade as $A$. rubra, but the differences in shade tolerance does not account for these results. While thinning typically reduces tree-to-tree variation, the fewer numbers of trees left after $7 \mathrm{~m}^{2} /$ ha treatment created more variation among trees than would be expected with regard to height growth. Perhaps the greater number of trees that were left after thinning to create the higher basal-area treatments served to average out the effects from extreme growth behaviors, thusresulting in lower mean values of $\mathrm{G}_{\mathrm{dh} / \mathrm{h}}$ for the higher basalarea treatments. 
The predominantly positive values of $\mathrm{G}_{\mathrm{dv} / \mathrm{dh}}, \mathrm{G}_{\mathrm{dAl} / \mathrm{dh}}$, and $\mathrm{G}_{\mathrm{dh}}$ support the widely held hypothesis that aboveground growth in tree populations is asymmetric. However, positive values observed in the lowest competition levels indicate that competition is not necessary for positive growth dominance indexes. Variation in microsite conditions or genotypes present would be expected to create disproportionate growth potential among trees independent of competition. Furthermore, trees react to shade in ways that reduce the unequal distribution of growth rates and size, thus reducing the degree of inequity expected with asymmetric competition.

Trees have been shown to have shade avoidance mechanisms that sense shade from changes in light quality due to shade and that sense mechanical perturbation. Shade light contains more far-red light relative to red light due to reflections and transmissions of shortwave radiation from and through leaves. The changes in spectral quality of shade light induces changes in the light sensitive phytochrome system, which stimulates elongated internodes in plants. Gilbert et al. (2001) demonstrated a chain of relationships starting with projected leaf effects on the red-far red ratios and red-far red ratios effects on height growth for three hardwood species allowing trees to counter shading effects. Koch et al. (2004) noted that the tallest trees occur in locations with abundant soil moisture and shelter from strong winds. Trees can sense mechanical perturbation (Jaffe 1973, Telewski 2021) causing the opposite effect on internode elongation than the phytochrome shade avoidance mechanism. The possible sheltering effect of neighboring trees was demonstrated by Jacobs (1954) who found that guying $P$. radiata trees increased the height growth compared to similar trees allowed to sway naturally. In a study with $P$. contorta, Meng et al. (2006) also demonstrated the sheltering effect on height in plots where groups of trees were tethered together to minimize swaying. They found that tethering significantly increased height over untethered trees. Based on these studies, relative height growth of shorter trees could be maintained by the sheltering effect of taller trees. On the other hand, height growth can be slowed by lack of shade and increased exposure to wind (Nagashima and Hikosaki 2012).

Contrary to common assumptions about one-sided competition for light, growing in the shade of a taller tree may be beneficial with respect to gas exchange. Young trees growing under a sparse canopy can keep stomata open longer during clear days by decreasing leaf temperature and vapor pressure gradients (Dalton and Messina 1995). Gu et al. (2002) through simulation, showed better quantum efficiencies of forest canopies illuminated with diffuse light compared to canopies receiving direct beam radiation and more linear responses of canopy photosynthesis to diffuse light than direct light. Alton et al. (2007) in investigating the possible effect of increased cloud cover due to future atmospheric conditions, found enhanced gross primary productivity in forest stands when diffuse radiation comprised more than half of the total solar radiation impinging on the canopy. Furthermore, Kuuluvainen and Pukkala (1987) calculated the three-dimensional probability of shading in forest stands and found prominent valleys in probability between trees. The canopy model varied with tree density and crown shape. Given intercrown abrasion (Putz 1984; Long and Smith 1992), canopies always have space between crowns, maintaining low shading probabilities between trees.

\section{Stand dynamics}

Based on our results, competition effects stand dynamics are linked to the temporal dynamics of $G_{d A l / d}$. and $G_{d h}$. Because of the linear relationship between $G_{d A l} / d h$ and $G_{d v / d h}$, competition effects on $G_{d A l / d h}$ can be assumed to be nearly identical to competition effects on $\mathrm{G}_{\mathrm{dv} / \mathrm{dh}}$. Values of $\mathrm{G}_{\mathrm{dv} / \mathrm{dh}}$ are generally positive, increasing slightly with competition. This indicates that the potential distribution of stem growth among trees in these studies is disproportionate with height rank with the tallest trees always adding more stem volume with each unit of height growth than shorter trees; increasing competition will exacerbate the inequity in growth potential. Realized stem growth per year is determined by the actual, and the actual distribution of stem growth will be determined by the distribution of height growth among trees. If $\mathrm{G}_{\mathrm{dh}}>0$, the inequity in volume per year will be increase; if $\mathrm{G}_{\mathrm{dh}}<0$, the distribution of volume growth per tree will become more equitable, i.e., more proportional to height at the beginning of the measurement period. The distribution of realized stem growth per tree will not change the distribution of marginal height costs and benefits unless the growth increases the intensity of competition within the population; trees will just change positions along the cumulative distribution curves.

\section{Conclusions}

The hypothesis that competition for light causes trees to trade physical support for photosynthetic potential is not supported by these results if the expectation under the hypothesis is that greater inequity in marginal height cost is offset by no change in the distribution of marginal height benefit. However, $\mathrm{G}_{\mathrm{dv} / \mathrm{dh}}$ and $\mathrm{G}_{\mathrm{dAl} / \mathrm{dh}}$ are linearly related with for these species. For $A$. rubra, the slope is less than 1 , meaning that as competition increases, $G_{d A l / d h}$ becomes less than $G_{d v / d h}$, which is consistent with the hypothesis. The dominance indexes for the two conifers is greater than one, resulting in $\mathrm{G}_{\mathrm{dAl} / \mathrm{dh}}$ becoming increasingly less than $\mathrm{G}_{\mathrm{dv} / \mathrm{dh}}$ as competition increases. The hypothesis that competition causes greater inequity in relative height growth is generally supported with these results. The strength of support for this 
hypothesis varied by species with the shade intolerant $A$. rubra providing the strongest support and the more shade tolerant $P$. menziesii providing the least support.

The results suggest that competition effects on marginal height benefit translate to marginal height cost through biomechanical relationships between crown size and structure and stem dimensions. Competitive effects on stand dynamics can therefore be linked to a basic tree morphology that scales with height. Realized additions of stem volume and foliage per growing season are determined by the distribution of relative height growth. The rate of change in stem and foliage accumulation per growing season is species-specific function of competition effects on relative height growth.

\section{Declarations}

\section{Author contributions}

TJD: Conceived the hypothesis, conducted analyses, wrote the first draft. CAH, AWD, \& BJP: Contributed data, participated in revising the drafts. All authors have read and approved the final manuscript

Competing Interests: The authors have no relevant financial or non-financial interests to disclose.

\section{Acknowledgements}

Major support was provided by the USDA Forest Service Northern, Rocky Mountain, and Pacific Northwest Research Stations. We thank Dr. D.E. Hibbs and the Oregon State University Hardwood Silviculture Cooperative for allowing a portion of their Alnus rubra data to be part of this study, and Dr. M. Kaller for comments concerning statistics and mathematics. This project was supported in part with Mclntire-Stennis funds under LAB94307. Published with the approval of the Director of the Louisiana Agricultural Experiment Station as publication No.

\section{Data availability}

Data for Pseudotsuga menziesii is available at https://doi.org/10.2737/RDS-2018-0055. Arrangements to access the Pinus resinosa data can be made by contacting BJ Palik. Contact the Oregon State University Hardwood Silviculture Cooperative to access the Alnus rubra data.

\section{References}

1. Alton PB, North PR, Los SO (2007) The impact of diffuse sunlight on canopy light-use efficiency, gross photosynthetic product and net ecosystem exchange in three forest biomes. Glob Change Biol 13(4):776-787

2. Assmann E (1970) The Principles of Forest Yield Study: Studies in the Organic Production, Structure, Increment and Yield of Forest Stands. Pergamon Press Ltd., p 492

3. Binkley D (2004) A hypothesis about the interaction of tree dominance and stand production through stand development. For Ecol Manag 190(2-3):265-271

4. Bruce D, DeMars DJ (1974) Volume equations for second-growth Douglas-fir, vol 239. USDA Forest Service Research Note PNW-, $p$ 5p

5. Cannell MGR, Rothery P, Ford ED (1984) Competition within stands of Picea sitchensis and Pinus contorta.Annals of Botany53(3)

6. Cole WG, Lorimer CG (1994) Predicting tree growth from crown variables in managed northern hardwood stands. For Ecol Manag 67(13):159-175

7. Dalton CT, Messina MG (1995) Water relations and growth of loblolly pine seedlings planted under a shelterwood and in a clear-cut. Tree Physiol 15(1):19-26

8. Dean TJ (2001) Potential effect of stand structure on belowground allocation. Forest Science 47(1):69-76

9. Dean TJ (2004) Basal area increment and growth efficiency as functions of canopy dynamics and stem mechanics. Forest Science 50(1):106-116

10. Dean TJ, D’Amato AW, Palik BJ, Battaglia MA, Harrington CA (2021) A Direct Measure of Stand Density Based on Stand Growth. Forest Science 67(1):103-115

11. Dean TJ, Jerez M, Cao QV (2013) A simple stand growth based an canopy dynamics and biomechanics. Forest Science 59(3):335-344

12. Dean TJ, Long JN (1986) Validity of constant-stress and elastic instability principles of stem formation in Pinus contorta and Trifolium pratense. Ann Botany 54:833-840

Page 12/19 
13. Dean TJ, Roberts SD, Gilmore DW, Maguire DA, Long JN, O'Hara KL, Seymour RS (2002) An evaluation of the uniform stress hypothesis based on stem geometry in selected North American conifers. Trees Structure and Function 16(8):559-568

14. Dean TJ, Roberts SD, Seymour RS (2013) Toward developing a direct relation between gross volume increment and stand density. Can J For Res 49(9):852-860

15. Falster DS, Westoby M (2003) Plant height and evolutionary games. Trends Ecol Evol 18(7):337-343

16. Fernández ME, Tschieder EF, Letourneau F, Gyenge JE (2011) Why do Pinus species have different growth dominance patterns than Eucalyptus species? A hypothesis based on differential physiological plasticity. For Ecol Manag 261(6):1061-1068

17. Fernández-Tschieder E, Binkley D (2018) Linking competition with Growth Dominance and production ecology. For Ecol Manag 414:99107

18. Forrester DI (2019) Linking forest growth with stand structure: Tree size inequality, tree growth or resource partitioning and the asymmetry of competition. For Ecol Manag 447:139-157

19. Fowler GW (1997) Individual tree volume equations for red pine in Michigan. North J Appl For 14(2):53-58

20. Gilbert IR, Jarvis PG, Smith H (2001) Proximity signal and shade avoidance differences between early and late successional trees. Nature 411(6839):792-795

21. Gu L, Baldocchi D, Verma SB, Black TA, Vesala T, Falge EM, Dowty PR (2002) Advantages of diffuse radiation for terrestrial ecosystem productivity. Journal of Geophysical Research: Atmospheres 107(D6):ACL 2-1-ACL 2-23

22. Harrington CA (1990) Alnus rubra Bong. In: Burns, R.M. and Honkala (comp), Silvics of North America: Volume 2, Hardwoods. Agric. Handb. 654, U.S. Dept. Agric. For. Serv. Washington, D.C. P. 116-123

23. Harrington C (2018) Douglas-fir levels of growing stock study (LOGS) data from the Pacific Northwest. Fort Collins, CO: Forest Service Research Data Archive. Available online at https://doi.org/10.2737/RDS-2018-0055; last accessed September 15, 2020.

24. Helgerson OT, Cromack K, Stafford S, Miller RE, Slagle R (1988) Equations for estimating aboveground components of young Douglas-fir and red alder in a coastal Oregon plantation. Canadian Journal Forest Research 18:1082-1085

25. Hermann RK, Lavender DP (1990) Pseudotsuga menziesii (Mirb.) Franco. In: Burns, R.M. and Honkala (comp), Silvics of North America: Volume 1, Conifers. Agric. Handb. 654, U.S. Dept. Agric. For. Serv. Washington, D.C. P. 527-540

26. Hibbs DE, Bluhm AA, Garber SM (2007) Stem taper and volume of managed red alder. West J Appl For 22(1):61-66

27. Iwasa Y, Cohen D, Leon JA (1985) Tree height and crown shape, as results of competitive games. J Theor Biol 112(2):279-297

28. Jacobs MR (1954) The effect of wind sway on the form and development of Pinus radiata D. Don. Aust J Bot 2:35-51

29. Jaffe MJ (1973) Thigmomorphogenesis: The response of plant growth and development to mechanical stimulation. Planta 114(2):143-157

30. King DA (1990) The adaptive significance of tree height. Am Nat 135(6):809-828

31. King DA (2005) Linking tree form, allocation and growth with an allometrically explicit model. Ecol Model 185(1):77-91

32. Koch GW, Sillett SC, Jennings GM, Davis SD (2004) The limits to tree height. Nature 428:851-854

33. Kuuluvainen T, Pukkala T (1987) Effect of crown shape and tree distribution on the spatial distribution of shade. Agric For Meteorol 40(3):215-231

34. Littell RC, Milliken GA, Stroup WW, Wolfinger RD, Schabenberger O (2006) SAS for Mixed Models, Second Edition. SAS Institute, Cary, N.C

35. Long JN, Smith FW (1992) Volume increment in Pinus contorta var. latifolia: the influence of stand development and crown dynamics. For Ecol Manag 53(1-4):53-64

36. Lundqvist L, Elfving BR (2010) Influence of biomechanics and growing space on tree growth in young Pinus sylvestris stands. For Ecol Manag 260(12):2143-2147

37. Maguire DA, Bennett WS (1996) Patterns in vertical distribution of foliage in young coastal Douglas-fir. Can J For Res 26:1991-2005

38. Mäkelä A (1985) Differential games in evolutionary theory: Height growth strategies of trees. Theor Popul Biol 27(3):239-267

39. Mattheck C (1990) Why they grow, how they grow: the mechanics of trees. Arboricultural Journal 14(1):1-17

40. McMahon TA, Kronauer RE (1976) Tree structures: deducing the principle of mechanical design. J Theor Biol 59:433-466

41. Meng SX, Lieffers VJ, Reid DEB, Rudnicki M, Silins U, Jin M (2006) Reducing stem bending increases the height growth of tall pines. J Exp Bot 57(12):3175-3182

42. Metzger K (1893) Der Wind als massgebender Faktor für das Wachtsum der Bäume. Mundener Forstliche Hefte 3:35-86

43. Morgan J, Cannell MGR (1994) Shape of tree stems - a re-examination of the uniform stress hypothesis. Tree Physiol 14(1):49-62 
44. Nagashima H, Hikosaka K (2012) Not only light quality but also mechanical stimuli are involved in height convergence in crowded Chenopodium album stands. New Phytol 195(4):803-811

45. Niklas KJ, Spatz HC (2012) Plant physics. University of Chicago Press

46. Niklas KJ, Spatz HC (2000) Wind-induced stresses in cherry trees: evidence against the hypothesis of constant stress levels. Trees Structure and Function 14(4):230-237

47. Penner M, Deblonde G (1996) The relationship between leaf area and basal area growth in jack and red pine trees. For Chron 72(2):170175

48. Putz FE (1984) Mechanical abrasion and intercrown spacing. Am Midl Nat 112(1):24-28

49. Rudolf PO (1990) Pinus resinosa Ait. In: Burns, R.M. and Honkala (comp), Silvics of North America: Volume 1, Conifers. Agric. Handb. 654, U.S. Dept. Agric. For. Serv. Washington, D.C. P. 442-455

50. Skovsgaard JP, Vanclay JK (2008) Forest site productivity: a review of the evolution of dendrometric concepts for even-aged stands. Forestry 81(1):13-31

51. Telewski FW (2021) Mechanosensing and Plant Growth Regulators Elicited During the Thigmomorphogenetic Response. Frontiers in Forests and Global Change 3:147

52. Trouvé R, Bontemps J-D, Seynave I, Collet C, Lebourgeois F (2015) Stand density, tree social status and water stress influence allocation in height and diameter growth of Quercus petraea (Liebl.). Tree Physiol 35(10):1035-1046

53. Uzoh FCC, Oliver WW (2006) Individual tree height increment model for managed even-aged stands of ponderosa pine throughout the western United States using linear mixed effects models. For Ecol Manag 221(1-3):147-154

54. Vanninen P, Mäkelä A (2005) Carbon budget for Scots pine trees: effects of size, competition and site fertility on growth allocation and production. Tree Physiol 25(1):17-30

55. Weiner J, Thomas SC (1986) Size variability and competition in plant monocultures. Oikos 47:211-222

56. Weiskittel AR, Hann DW, Hibbs DE, Lam TY, Bluhm AA (2009) Modeling top height growth of red alder plantations. For Ecol Manag 258(3):323-331

57. West PW (2014) Calculation of a Growth Dominance Statistic for Forest Stands. Forest Science 60(6):1021-1023

58. West PW, Jackett DR, Sykes SJ (1989) Stresses in, and the shape of, tree stems in forest monoculture. J Theor Biol 140:327-343

59. Wilson BF, Archer RR (1979) Tree design: some biological solutions to mechanical problems. Bioscience 29:293-298

\section{Figures}



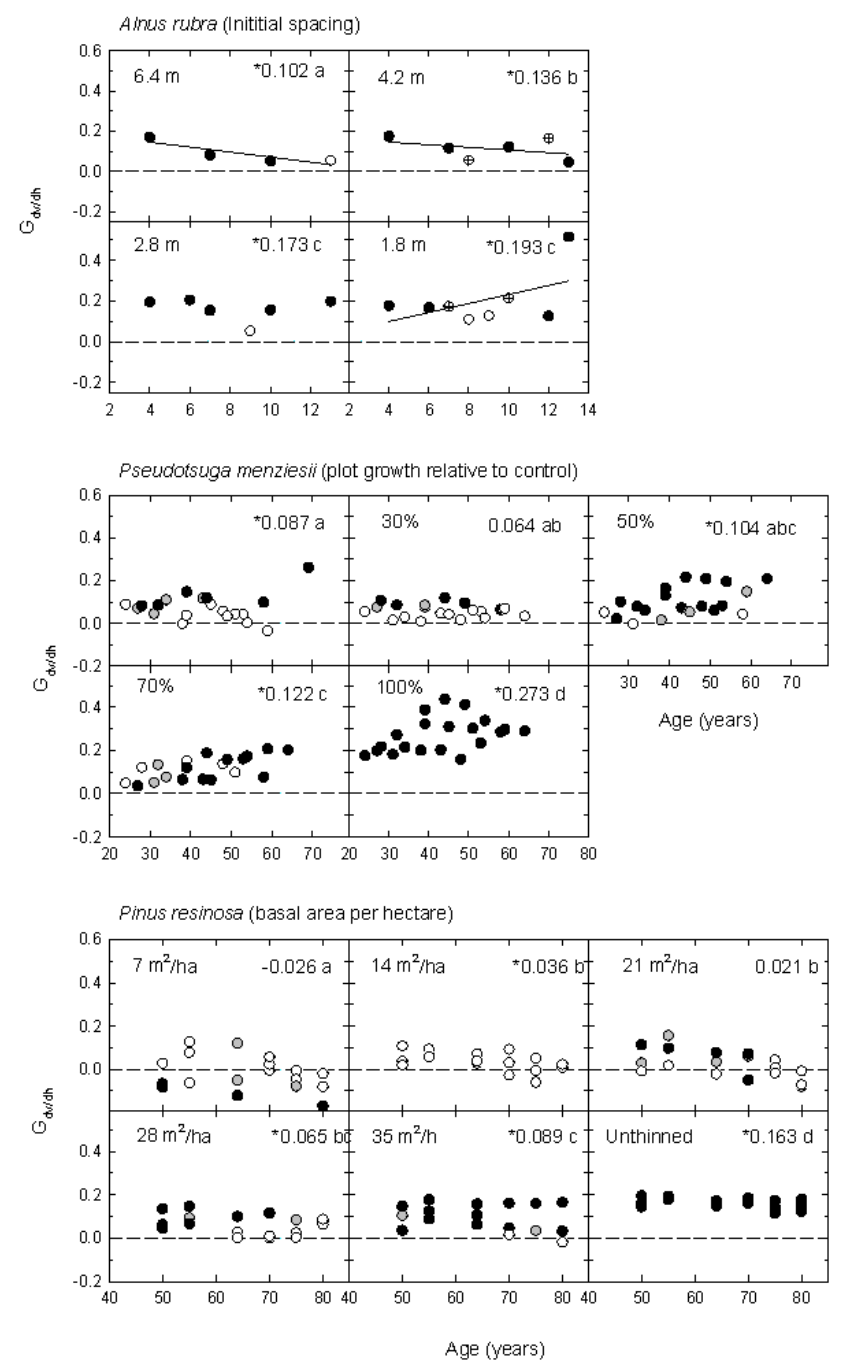

\section{Figure 1}

Dominance indexes for proportion of cumulative stem volume increment per height increment and proportion of cumulative height ( $\left.G_{\mathrm{dv} / \mathrm{dh}}\right)$ by treatment and age for Alnus rubra, Pseudotsuga menziesii, and Pinus resinosa. Each data point is the mean of replicated plots for each planting density or level of growing stock. Open circles with an interior cross indicate only one plot for that treatment and age combination. Fill colors of circles indicate the respective probabilities $(P)$ for testing $\mathrm{H}_{0}$ :

with a two-tailed, $t$ test. Black fill represents $P<=0.05$; grey fill represents $0.05>P<=0.10$; and white fill represents $P>0.10$. Values in the upper right of figures are least squares means of $\mathrm{G}_{\mathrm{dv} / \mathrm{dh}}$ adjusted for age from mixed-model, covariance analyses. Letters beside the numbers indicate groups of means that are not significantly different according to probability of the difference $<0.1$. Asterisks indicate whether an age-adjusted mean is significantly different than zero $(P<0.10)$. Lines are least-square fits when slope are significant between $G_{d h t}$ and age. 

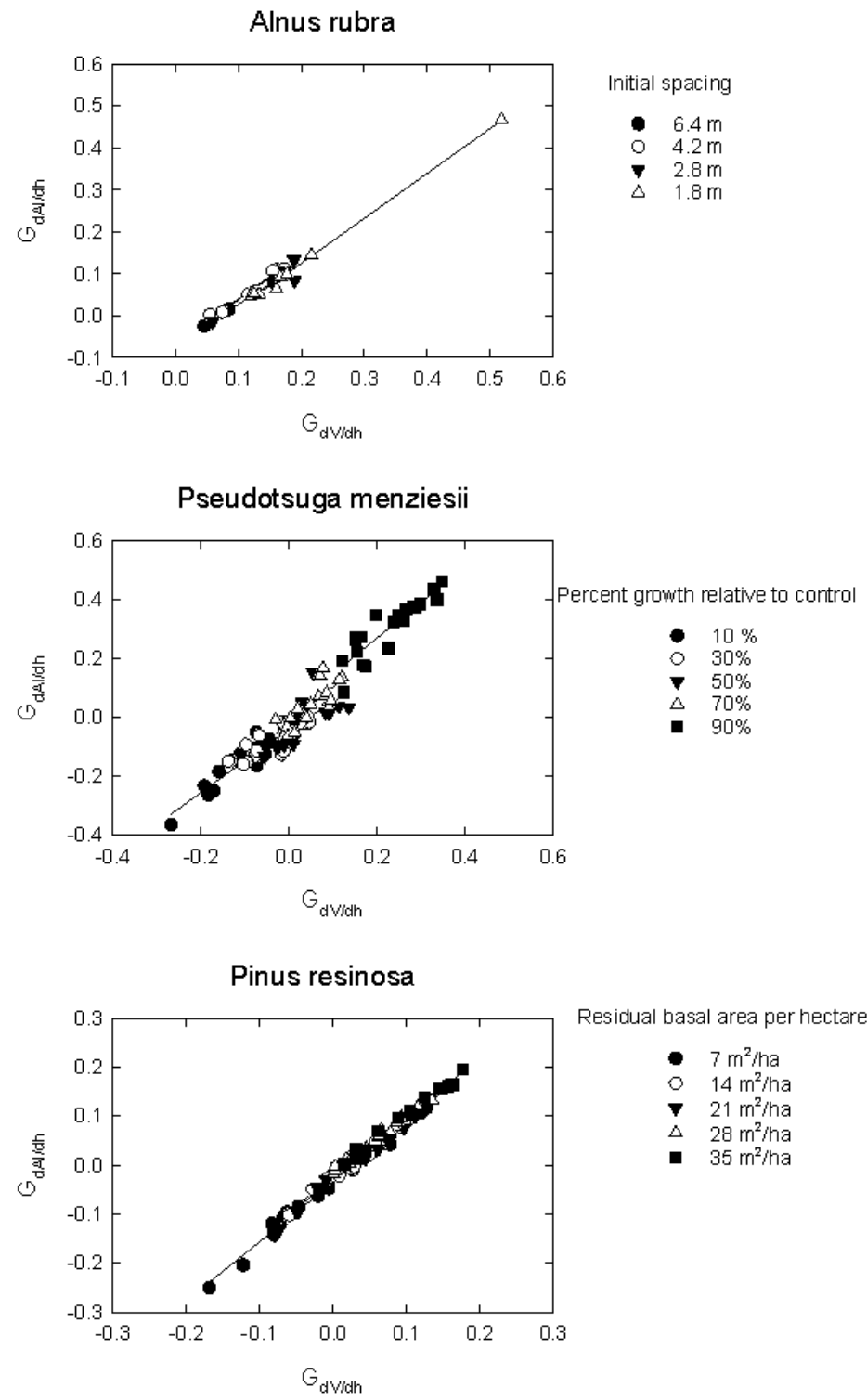

\section{Figure 2}

Scattergrams of growth dominance indexes for proportion of cumulative leaf area added per height increment and proportion of cumulative height $\left(\mathrm{G}_{\mathrm{dA} / \mathrm{dh}}\right)$ and growth dominance indexes for proportion of cumulative stem volume added per height increment and proportion of cumulative height $\left(\mathrm{G}_{\mathrm{dv} / \mathrm{dh}}\right)$ for each species, treatment combination, and measurement period. 



\section{Figure 3}

Dominance coefficients for proportion of cumulative height increment and proportion of cumulative height $\left(\mathrm{G}_{\mathrm{dht}}\right)$ by treatment and age for Alnus rubra, Pseudotsuga menziesii, and Pinus resinosa. Plotting symbols and values are described in Figure 1. 



Percent growth relative to control

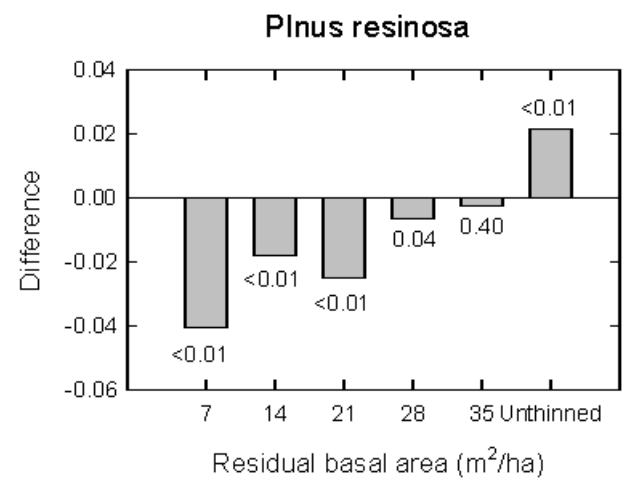

\section{Figure 4}

Mean differences between $\mathrm{G}_{\mathrm{dAl} / \mathrm{dh}}$ and $\mathrm{G}_{\mathrm{dv} / \mathrm{dh}}$ by species and treatment. Means are adjusted for age. Probabilities of greater values of Student's $t$ for the null hypothesis than means $=0$. Negative differences indicate that $G_{d v / d h}>G_{d A l} / d h$. 

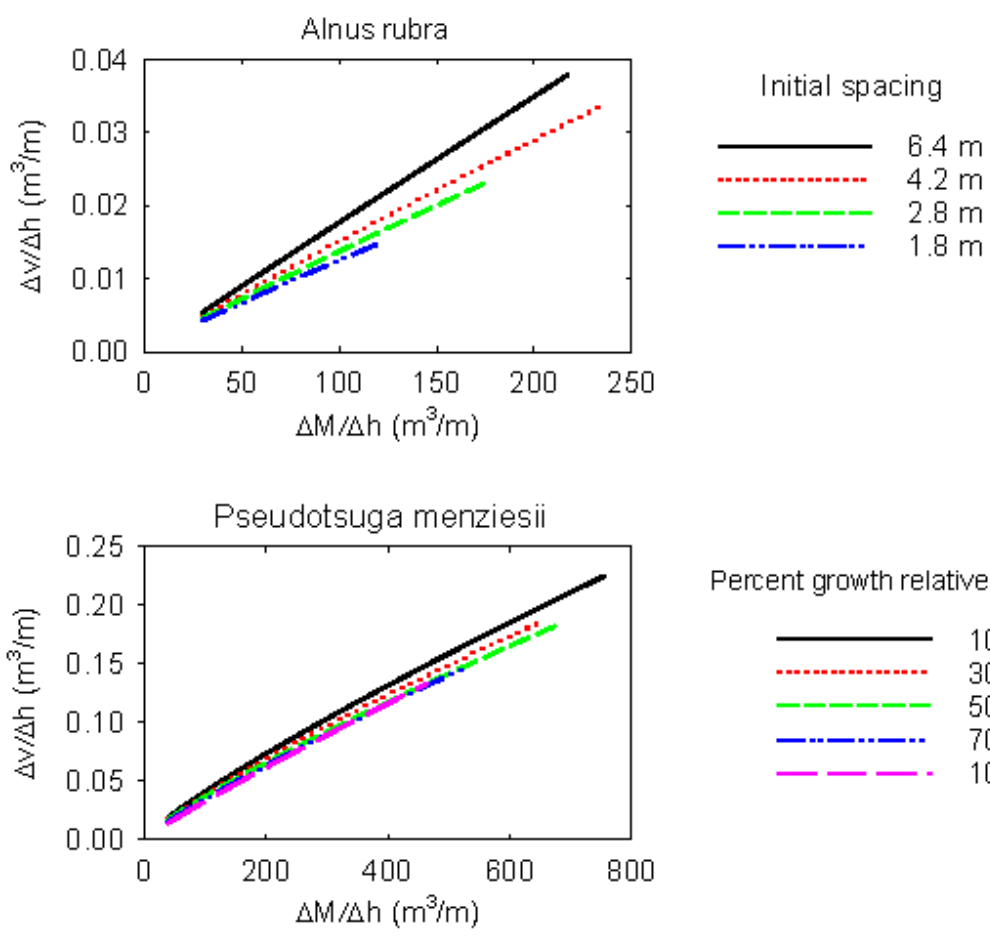

Percent growth relative to control


Residual basal area per hectare

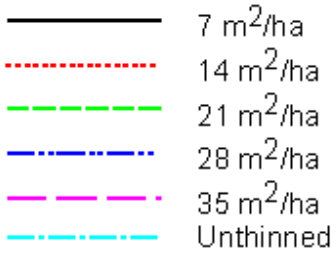

Figure 5

Slopes between individual tree values of stem volume increment per unit height increment and the increment in bending moment (DM) per height increment by initial planting density (Alnus rubra), level of growing stock (Pseudotsuga menziesii), and basal area (Pinus resinosa). Lines fit with ordinary least squares with autoregressive covariance. Extent of lines reflects range of data. 